\title{
Temporal Modified Speech Perception in Dyslexia
}

\author{
Caroline Jacquier (jacquier@isc.cnrs.fr) \\ Fanny Meunier (fanny.meunier@univ-lyon2.fr) \\ Laboratoire Dynamique Du Langage \\ 14 avenue Berthelot \\ 69007 Lyon, France
}

\begin{abstract}
The phonological or the auditory hypotheses are the two main views still debated to explain nature and origin of dyslexia. In the experiments presented we investigated the auditory temporal processing deficit in dyslexic adults. By timecompression of rapid acoustic cues, we explored their capacities of extraction and analyze of this acoustic features (voice onset-time and second formant transition). Moreover, we evaluated their abilities to reconstruct a degraded speech signal. Compared with controls, dyslexics exhibit deficit in time-compressed speech perception, the impairment is stronger for voicing feature than place of articulation. The temporal information would be inefficiently extracted and analyzed by dyslexics.
\end{abstract}

Keywords: Dyslexia, Speech Perception, Auditory Temporal Processing.

\section{Introduction}

Dyslexia is defined as learning and reading problems in spite of neurological or sensory deficits, education and social background and normal IQ. In spite of numerous researches, neurological and cognitive basis of dyslexia are still debated. There are two major competing theories of the cognitive deficit: the phonological (Snowling, 2000; Ramus, 2003) and the auditory hypothesis (Tallal, 1980). The first one underlines specific cognitive deficits to representation and processing of speech sounds: dyslexic individuals would have a degraded phoneme representation that is not efficient in the conversion into grapheme. This conversion is essential in the phonological pathway for reading and writing abilities (Mody, Studdert-Kennedy, \& Brady, 1997). The second hypothesis highlights more precisely a more basic auditory deficit: it is the temporal resolution that would be deficient. Dyslexics exhibit deficiencies in perceiving some brief sounds and rapid transitions. What this means is that speech sounds like phonemes are poorly differentiated by subjects with dyslexia. The inabilities in auditory temporal processing would induce poor phonological code representation. Thus, it is postulated that dyslexics have a general auditory deficit in temporal processing (Tallal, Galaburda, Llinás, \& von Euler, 1993). Indeed, two complementary studies have shown that an intensive training of language impaired children with temporally stretched speech improves their language ability (Merzenich, Jenkins, Johnston, Schreiner, Miller, \& Tallal, 1996; Tallal, Miller, Bedi, Byma, Wang, Nagarajan, Schreiner, Jenkins, \& Merzenich, 1996). However, this improvement has not been clearly demonstrated for dyslexic deficits. Otherwise, fast speech studies have underlined that artificially time-compressed speech was easier to process than naturally produced fast speech (Janse, 2003). One of the processing disadvantages of naturally produced fast speech is due to its changed timing, the temporal organisation of spoken language would be relatively unimportant at a normal rate, but that it may become more critical to comprehension, the more the speech rate is increased (Foulke, 1971). Thus, following this, we can hypothesis that an acceleration of the speech signal rate would change the speech perception and comprehension of dyslexic adults.

Our study investigated the auditory temporal processing of accelerated speech on dyslexic adults and adults without language impairments. Our hypothesis is that dyslexics would have more difficulties to process artificially timecompressed speech than controls. Moreover, we focused the time-compression on rapid transition and brief sound of the speech signal. In the present study, we focused on the temporal modulation of two acoustic cues: the Voice OnsetTime (VOT) and the second Formant Transition (FT2) mainly implicated in speech perception and comprehension. Indeed, the speech signal is a complex combination of a wide range of acoustic cues. All acoustic cues do not have the same effectiveness for speech restoration. Previous studies have underlined the importance of acoustic cues in speech perception (Kent, \& Moll, 1969; Lisker, \& Abramson, 1967; Serniclaes, 1987).

In one hand, VOT is one of the primary acoustic cues contrasting syllable-initial stop consonants across languages both in production and perception. According to Lisker and Abramson (1964), the VOT is defined as the time interval between the plosive release and the onset of low-frequency periodicity generated by rhythmic vocal cord vibration. If we assign a value of zero to the instant of stop release, unvoiced stops $(/ \mathrm{p} /, / \mathrm{t} /$ and $/ \mathrm{k} /)$ are then measured as a positive VOT, because there is a delay between the stop 
release and the voicing onset, whereas voiced stops (/b/, /d/ and $/ g /$ ), with a laryngeal vibration that continues from closure up to the moment of release are measured as a negative VOT. Thus, VOT values correspond to the degree of voicing. In other hand, formant transition corresponds to the rapid changes in formant frequency which occurs at the moment of release of the stop constriction. Rapid changes in formant frequency are crucial in identifying sound segments. The transition of the second formant functions as a cue for determining the place of articulation of the plosive consonants. Ziegler, Pech-Georgel, George, Alario and Lorenzi (2005) investigated the perception of phonetic features such as voicing, manner and place of articulation in the presence of masking noise on specific language impairment (SLI) children. Their results showed that perception for all phonetic features were impaired and strongly for voicing. The extraction and analyze of the acoustic cues were inefficient. Our hypothesis is that dyslexics would show more or less specific impairment for each acoustic cue compared to controls. Moreover, we expected that our results would be in favor of the auditory hypothesis because of the nature of our task. Indeed, in the auditory non-word identification task, dyslexics should not use the phonological pathway. Their task should be at a very basic level of auditory and linguistic processing.

A huge problem in speech perception and comprehension is the variable nature of the acoustic patterns. Modulations of those acoustic details induce some variability in the speech comprehension. However, speech comprehension in normal hearing individuals is an impressively robust cognitive faculty that resists to the important variability existing in acoustical properties of speech signal. In this context, it has been demonstrated that speech remained identifiable and to some extent intelligible even after important physical manipulations as drastic filtering, spectral decompositions or time-reversions (see for example, Meunier, Cenier, Barkat, \& Magrin-Chagnolleau, 2002; Warren, 1970). The cognitive system appears to be able to compensate and reconstruct even a corrupted speech signal. However, it appears that we are not all on an equal footing faced with the perception and comprehension of degraded speech. The necessary cognitive restoration seems to rely on individual abilities. Moreover, this reconstruction ability depends on the type of distortion and on its importance. In our study, we may expect that dyslexics would have quantitatively and qualitatively different cognitive restoration abilities than controls, i.e. their percentage of errors would be higher and it is likely that their nature would be different.

Our aim was to investigate the acceleration effect of rapid acoustic cues on both groups and to yield results in accordance with the phonological or auditory theories of dyslexia. Moreover, cognitive restoration mechanisms should be less efficient in dyslexic group. We used an auditory identification task with CVCV non-words which were time-compressed on the duration of VOT and FT2 then control and dyslexic group were compared.

\section{Experimental Procedure}

\section{Participants}

Experiment 1: Voice Onset-Time Compression Data were collected from thirty two adults with dyslexia and thirty two controls. The mean age was $23.3(S D=5.5$, range $=16-35)$ for the dyslexics and $22.6(S D=5$, range $=18-39)$ years for the controls. Each dyslexic participant was matched to one of the controls on age and gender (Table 1).

Experiment 2: Formant Transition Compression Two groups were investigated in this experiment: the same 32 dyslexic adults and thirty two controls. The mean age was $23.3(S D=5.5$, range $=16-35)$ for the dyslexics and 22.6 $(S D=5$, range $=19-39)$ years for the controls. Each dyslexic participant was matched to one of the controls on age and gender (Table 1).

The dyslexia of the present participants had been independently diagnosed by a psychologist or a speech pathologist recently or at least at their majority. This was first documented when recruiting the subjects and then verified with a French dyslexia detection test (ODEDYS created by Jacquier-Roux, Valdois, \& Zorman, 2002) which is an analytic evaluation of the written language. This test is composed by the Alouette test (Lefavrais, 1965), reading, orthographic, metaphonological evaluations, a short term verbal memory task and a visual tasks. Control participants reported having no hearing problems and no history of speech problems whereas auditory thresholds were measured for each dyslexic participant and was at or better than $20 \mathrm{~dB}$ hearing level. All the participants were native speakers of French.

Table 1: Subject groups in experiment 1.

\begin{tabular}{|c|c|c|c|c|}
\hline & \multicolumn{2}{|c|}{ Experiment 1} & \multicolumn{2}{|c|}{ Experiment 2} \\
\hline & $\begin{array}{c}\text { Control } \\
\text { adults } \\
(N=32)\end{array}$ & $\begin{array}{c}\text { Dyslexic } \\
\text { adults } \\
(N=32)\end{array}$ & $\begin{array}{c}\text { Control } \\
\text { adults } \\
(N=32)\end{array}$ & $\begin{array}{c}\text { Dyslexic } \\
\text { adults } \\
(N=32)\end{array}$ \\
\hline Mean Age (yrs) & 22.6 & 23.3 & 22.6 & 23.3 \\
\hline Gender male & 10 & 10 & 10 & 10 \\
\hline female & 22 & 22 & 22 & 22 \\
\hline
\end{tabular}

\section{Material}

The experiment consisted of an auditory identification nonword task. The participants were asked to identify 80 nonwords. The material consisted of 64 disyllabic CVCV nonwords and $16 \mathrm{VCV}$ fillers. Four stop consonants $(/ \mathrm{b} /, / \mathrm{d} /, / \mathrm{p} /$ and $/ \mathrm{t} /$ ) and two vowels $(/ \mathrm{a} /$ and $/ \mathrm{i} /$ ) were combined to form each stimulus. Each consonant occurred with every other consonant in both syllable positions and with two different vowels $(4 \mathrm{C} 1 \times 4 \mathrm{C} 2 \times 2 \mathrm{~V} 1 \times 2 \mathrm{~V} 2=64 \mathrm{CVCV})$.

The stimuli were recorded by a native male French speaker in a sound-proof cabin. The files were saved as wave files and sampled at $22 \mathrm{kHz}$ (stereo, 16 bits).

The duration of each acoustic cue (VOT and FT2) were manually measured for each item with Praat software 
(Figure 1). Moreover, VOT was manually segmented from the onset of periodic oscillations and the onset of release of the consonant: VOT is positive for unvoiced stop and negative for voiced stop consonants. FT2 was delimited from the moment of rapid change of the direction of the second formant, during the transition between consonant and vowel, to the steady-state part of the vowel (formants parallels). In a first experiment, only the duration of VOT was accelerated (Experiment 1) and in a second experiment, only FT2 was time-compressed (Experiment 2). The duration of the acoustic cue was time-compressed according to four experimental conditions:

$\begin{array}{ll}\text { - } & 100 \% \\ \text { - } & 50 \% \\ \text { - } & 25 \% \\ & 0 \%\end{array}$

$$
\begin{aligned}
& =\text { control condition } \\
& =50 \% \text { of original duration } \\
& =25 \% \text { of original duration } \\
& =\text { totally deleted }
\end{aligned}
$$

The time-compression is made using the Pitch-Synchronous Overlap Add (PSOLA) time scaling technique, used in the Praat software. Segmented parts of the waveform can be time-compressed, while the rest of the waveform remains unaffected. In this way, each syllable can be selectively time-compressed.

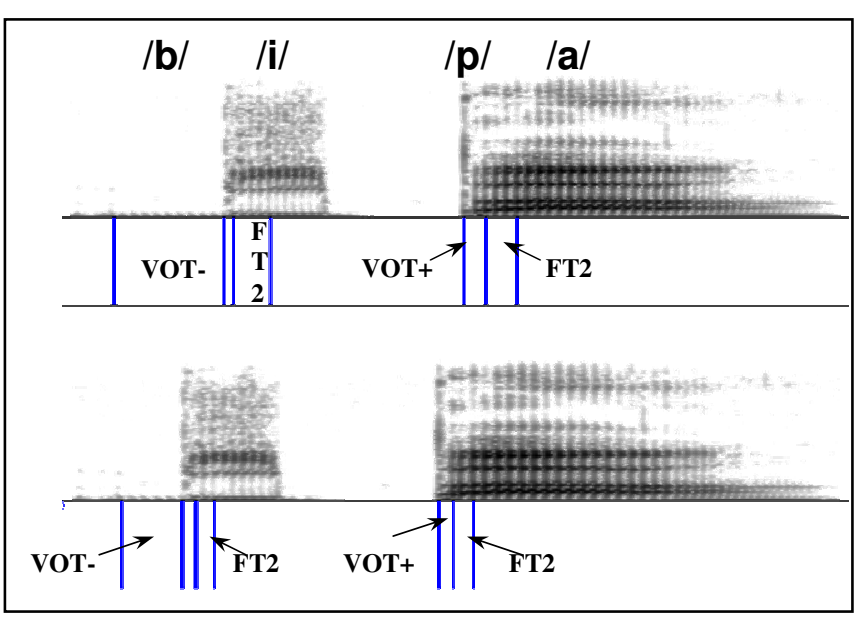

Figure 1: Spectrogram of non-word [bipa].

VOT of [b] is negative and VOT of [p] is positive. Control condition $100 \%$ _100\% (in top) and time-compression condition 50\%_50\% (in bottom).

\section{Procedure}

The auditory identification non-words task was preceded by a practice session containing 12 spoken examples, which were meant to familiarize participants with the task. After this, 80 stimuli were presented to the participants once. The stimuli were randomized across subjects. Participants were seated in a silent room facing a computer monitor. The stimuli were delivered binaurally via headphones

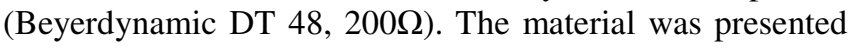
at a comfortable listening level. The subjects were informed that a speech signal, though not necessarily a word, was to be emitted. Control participants then had to type on a computer keyboard whatever they heard whereas dyslexic subjects had to repeat the stimuli. To avoid an additional stage of phonological processing, dyslexics were not ask to write down the stimuli. Indeed, we expected that dyslexics showed dysorthographical problems. Consequently, only the decoding-encoding auditory capacities would be evaluated. Each experiment took approximately 15 minutes to complete including the practice.

\section{Results}

In the next subsections, identification rates and errors' nature with accompanying statistics results are presented. We computed identification rates for stimuli across subjects, for consonants and for vowels.

\section{Identification rates}

Experiment 1: VOT Time-Compression We ran a 3-way ANOVA including as factors: Group (control, dyslexic), Position of consonant (attack, intervocalic) and Timecompression conditions $(100,50,25,0 \%)$. We observed a main effects of Group $[F(1,31)=28.56, p<.001]$, Position $[F(1,31)=15.99, p<.001]$ and Time-compression $[F(3,93)$ $=356.18, p<.001]$. Control group has a better identification rate $(89.6 \%)$ than dyslexic group $(83.6 \%)$ in this experiment. The identification rate of the intervocalic consonant $(88.3 \%)$ is better than the attack consonant identification rate $(84.9 \%)$. A post-hoc Newman-Keuls test showed that the identification rate is significantly lower at $25 \%$ and $0 \%$ of compression (90\% and $65 \%$ ) than at $100 \%$ and $50 \%(96.4 \%$ and $95 \%)$. In addition, we observed a significant interaction between Group and Position $[F(3,31)$ $=4.76, p<.05]$. A Position effect for the dyslexic group but not for the control group was obtained. For the dyslexic group, the intervocalic consonant is better identified than the attack consonant whereas there are no significant differences between both consonant positions for the control group. The interaction between Position and Timecompression was also significant $[F(3,93)=4.48, p<.01]$, this was mainly due to the effect of Position that is stronger for $100 \%$ and $50 \%$ compressions than for all the others compressions. Furthermore, we observed a Group effect at $100 \%$ and then for all conditions (Table 2) but the interaction between Group and Time-compression was not significant.

Table 2: Identification rates (\%) for VOT and FT2 compression experiments for Control vs. Dyslexic groups.

\begin{tabular}{clcccc}
\hline & & \multicolumn{2}{c}{ VOT compression } & \multicolumn{2}{c}{ FT2 compression } \\
\cline { 3 - 6 } & & $\begin{array}{c}\text { Control } \\
\text { adults }\end{array}$ & $\begin{array}{c}\text { Dyslexic } \\
\text { adults }\end{array}$ & $\begin{array}{c}\text { Control } \\
\text { adults }\end{array}$ & $\begin{array}{c}\text { Dyslexic } \\
\text { adults }\end{array}$ \\
\hline \multirow{4}{*}{$\mathrm{C}_{1}$} & $100 \%$ & 97.3 & 91.2 & 97.5 & 93.9 \\
& $50 \%$ & 95.5 & 87.9 & 98.2 & 92.4 \\
& $25 \%$ & 92.8 & 85.2 & 96.5 & 92 \\
& $0 \%$ & 70.1 & 59.2 & 85.2 & 80.5 \\
\hline \multirow{3}{*}{$\mathrm{C}_{2}$} & $100 \%$ & 99.6 & 97.5 & 99.6 & 98.2 \\
& $50 \%$ & 99 & 97.7 & 99.4 & 98.4 \\
& $25 \%$ & 94.7 & 87.3 & 99.6 & 97.3 \\
& $0 \%$ & 67.8 & 62.9 & 95.7 & 95.3 \\
\hline
\end{tabular}


A 2-way ANOVA including Group (control, dyslexic) and Phoneme $\left(\mathrm{C}_{1}, \mathrm{~V}_{1}, \mathrm{C}_{2}, \mathrm{~V}_{2}, \mathrm{CVCV}\right)$ showed main effects of Group $[F(1,31)=27.50, p<.001]$ and Phoneme $[F(4,124)=$ 417.42, $p<.001]$. Table 3 displays the significant interaction between Group and Phoneme $[F(4,124)=16.11$, $p<.001]$, significant effects of Group for $\mathrm{C} 1, \mathrm{C} 2$ and CVCV.

Experiment 2: FT2 Time-Compression A 3-way ANOVA including Group (control, dyslexic), Position of consonant (attack, intervocalic) and Time-compression conditions $(100 \%, 50 \%, 25 \%, 0 \%)$ reported main effects of Group $[F(1,31)=12.01, p<.01]$, Position $[F(1,31)=71.71, p<$ $.001]$ and Time-compression $[F(3,93)=81.61, p<.001]$. Control group has a better identification rate $(96.5 \%)$ than dyslexic group $(93.5 \%)$ in this experiment. The identification rate of the intervocalic consonant $(97.9 \%)$ is better than the attack consonant identification rate (92\%). A post-hoc Newman-Keuls test showed that the identification rate is significantly lower at $0 \%(89.2 \%)$ than at $100 \%, 50 \%$ and $25 \%$ of compression $(97.3 \%, 97.1 \%$ and $96.3 \%)$. The interaction between Group and Position $[F(1,31)=6.97, p<$ .05] and the interaction between Position and Timecompression also were significant $[F(3,93)=35.30, p<$ $.001]$. This was mainly due to the effect of the Group that is significant only for the attack consonant position $(p<.001)$; the identification of the attack consonant is more difficult for dyslexics. In addition, we observed a group effect as $100 \%$ and then for all conditions (Table 2) but the interaction was not significant.

A 2-way ANOVA including Group (control, dyslexic) and Phoneme $\left(\mathrm{C}_{1}, \mathrm{~V}_{1}, \mathrm{C}_{2}, \mathrm{~V}_{2}, \mathrm{CVCV}\right)$ showed main effects of Group $[F(1,31)=12.08, p<.01]$ and Phoneme $[F(4,124)=$ 133.34, $p<.001]$. Table 3 displays the significant interaction of the group and phoneme $[F(4,124)=9.60, p<$ $.001]$, significant effect of group for $\mathrm{C} 1$ and $\mathrm{CVCV}$.

Table 3: Identification rates (\%) for VOT and FT2 compression experiments for Control vs. Dyslexic groups. 2-way ANOVA: * p $<0.05, * * \mathrm{p}<0.01$, *** $\mathrm{p}<0.001$.

\begin{tabular}{lcccccc}
\hline & \multicolumn{3}{c}{ VOT Compression } & \multicolumn{3}{c}{ FT2 Compression } \\
\cline { 2 - 7 } & $\begin{array}{c}\text { Control } \\
\text { adults }\end{array}$ & $\begin{array}{c}\text { Dyslexic } \\
\text { adults }\end{array}$ & $\mathrm{p}$ & $\begin{array}{c}\text { Control } \\
\text { adults }\end{array}$ & $\begin{array}{c}\text { Dyslexic } \\
\text { adults }\end{array}$ & $\mathrm{p}$ \\
\hline $\mathrm{C}_{1}$ & 88.9 & 80.9 & $* * *$ & 94.3 & 89.7 & $* * *$ \\
$\mathrm{~V}_{1}$ & 99.7 & 99.1 & $\mathrm{~ns}$ & 99.9 & 99.9 & $\mathrm{~ns}$ \\
$\mathrm{C}_{2}$ & 90.3 & 86.3 & $* * *$ & 98.6 & 97.3 & $\mathrm{~ns}$ \\
$\mathrm{~V}_{2}$ & 99.8 & 99.3 & $\mathrm{~ns}$ & 100 & 99.9 & $\mathrm{~ns}$ \\
\cline { 2 - 7 } CVCV & 80.3 & 70.7 & $* * *$ & 92.9 & 87.5 & $* * *$ \\
\hline
\end{tabular}

\section{Errors' Nature}

Experiment 1: VOT Time-Compression Observation of confusions made by participants showed qualitative and quantitative error differences between both groups. Indeed, overall dyslexics make more errors than controls. Moreover, confusion matrixes reveal, in both groups, different type of errors according to the consonant position (Table 4, left part). The attack consonant is most of the time confounded with the unvoiced corresponding consonant $(/ \mathrm{b} /->/ \mathrm{p} /$ or $/ \mathrm{d} /-$ $>/ t /$ ) even at $100 \%$ (control condition) for dyslexics whereas the intervocalic consonant is more often confounded with the approximant liquid consonant $/ 1 /$.

Experiment 2: FT2 Time-Compression Dyslexic adults made more errors than control adults. The observation of Table 4 (right part) displays a main type of confusion that is a place of articulation error for voiced consonants $(/ \mathrm{b} /->/ \mathrm{d} /)$. This result is observed in both consonant positions for both groups but appears as from the control condition (100\%) for dyslexics. It is noteworthy that dyslexic adults present significant auditory non-words identification deficit in the control condition in which the speech signal is intact.

\section{Discussion}

In this paper, we investigated the speech perception processing in dyslexia. The phonological and auditory theories are still discussed to explain cognitive deficits in dyslexia. We studied the effect of time-compression of rapid acoustic cues on speech intelligibility by dyslexic subjects compared to control participants with no history of reading deficit. We compressed either the voicing phonetic features (Experiment 1: Voice Onset-Time) or the place of articulation phonetic features (Experiment 2: second Formant Transition). We wonder if the artificially timecompressed speech, in opposition to the lengthened speech signal (Merzenich, Jenkins, Johnston, Schreiner, Miller, \& Tallal, 1996; Tallal, Miller, Bedi, Byma, Wang, Nagarajan, Schreiner, Jenkins, \& Merzenich, 1996), would be improve dyslexic's performance in an auditory non-word identification task.

Overall, the main results showed a group effect; indeed dyslexic adults exhibit more difficulties to identify the temporal modified speech for both phonetic features (voicing and place of articulation). The acceleration of these rapid acoustic cues would disturb the extraction and the analysis of these temporal segments needed in speech perception. The temporal organisation seems to play an important role for dyslexics. Moreover, results of experiment 1 demonstrated that dyslexics had a stronger deficit of integration for the VOT than for the second formant transition. Indeed, the difference between control and dyslexic groups in experiment 1 affected the attack and the intervocalic consonants whereas in experiment 2 , only the attack consonant was sensible to a group effect. This result is in accordance with the strongly effect of voicing observed in Ziegler et al. study (2005). Thus, voicing feature might play a more important role in the discrimination between consonants in spite of the position consonant in non-word. And, place of articulation feature of the intervocalic consonant might be easy compensated by the signal redundancy.

Table 4: Confusion matrixes of plosive consonants. 
Experiment 1 Dyslexic group - Attack consonant

\begin{tabular}{|c|c|c|c|c|c|c|c|c|c|c|}
\hline & & $b$ & $\mathrm{~d}$ & $g$ & $p$ & $t$ & $k$ & 1 & f & nul \\
\hline \multirow{4}{*}{ ஃ̊ㅇ } & $\mathrm{b}$ & 114 & 3 & 0 & 9 & 0 & 0 & 0 & 0 & 2 \\
\hline & $d$ & 3 & 117 & 1 & 0 & 6 & 0 & 0 & 0 & 1 \\
\hline & $p$ & 0 & 3 & 0 & 117 & 6 & 0 & 0 & 0 & 2 \\
\hline & $\mathrm{t}$ & 0 & 2 & 0 & 5 & 119 & 2 & 0 & 0 & 0 \\
\hline \multirow{4}{*}{ ○ें } & $b$ & 121 & 2 & 0 & 4 & 0 & 0 & 0 & 0 & 1 \\
\hline & d & 2 & 119 & 0 & 0 & 6 & 0 & 0 & 0 & 1 \\
\hline & $p$ & 9 & 2 & 0 & 96 & 5 & 0 & 0 & 0 & 16 \\
\hline & $t$ & 0 & 1 & 0 & 8 & 114 & 0 & 0 & 0 & 5 \\
\hline \multirow{4}{*}{ 命 } & b & 117 & 3 & 0 & 6 & 0 & 0 & 0 & 0 & 2 \\
\hline & d & 1 & 120 & 0 & 1 & 5 & 0 & 0 & 0 & 1 \\
\hline & $p$ & 8 & 0 & 0 & 104 & 5 & 0 & 0 & 0 & 11 \\
\hline & $\mathrm{t}$ & 2 & 10 & 0 & 10 & 95 & 0 & 0 & 1 & 10 \\
\hline \multirow{4}{*}{ ㅇํㅇ } & $b$ & 90 & 9 & 0 & 14 & 0 & 0 & 0 & 0 & 15 \\
\hline & d & 4 & 108 & 0 & 2 & 14 & 0 & 0 & 0 & 0 \\
\hline & $p$ & 4 & 1 & 0 & 61 & 1 & 0 & 0 & 1 & 60 \\
\hline & $\mathrm{t}$ & 5 & 12 & 0 & 23 & 43 & 0 & 1 & 0 & 44 \\
\hline
\end{tabular}

Experiment 1 Control group - Attack consonant

\begin{tabular}{ccccccccccc}
\hline & & $\mathrm{b}$ & $\mathrm{d}$ & $\mathrm{g}$ & $\mathrm{p}$ & $\mathrm{t}$ & $\mathrm{k}$ & $\mathrm{v}$ & $\mathrm{m}$ & $\mathrm{nul}$ \\
\hline \multirow{2}{\circ}{} & $\mathrm{b}$ & 128 & 0 & 0 & 0 & 0 & 0 & 0 & 0 & 0 \\
$\circ$ & $\mathrm{d}$ & 0 & 124 & 0 & 0 & 4 & 0 & 0 & 0 & 0 \\
$\circ$ & $\mathrm{p}$ & 0 & 0 & 0 & 122 & 5 & 0 & 0 & 0 & 1 \\
& $\mathrm{t}$ & 0 & 1 & 0 & 1 & 124 & 2 & 0 & 0 & 0 \\
\hline \multirow{2}{\circ}{} & $\mathrm{b}$ & 128 & 0 & 0 & 0 & 0 & 0 & 0 & 0 & 0 \\
$\circ$ & $\mathrm{d}$ & 0 & 124 & 1 & 0 & 2 & 0 & 0 & 0 & 1 \\
$\circ$ & $\mathrm{p}$ & 4 & 0 & 0 & 116 & 0 & 0 & 0 & 0 & 8 \\
& $\mathrm{t}$ & 0 & 1 & 0 & 4 & 121 & 0 & 0 & 0 & 2 \\
\hline \multirow{3}{\circ}{} & $\mathrm{b}$ & 126 & 2 & 0 & 0 & 0 & 0 & 0 & 0 & 0 \\
$\stackrel{\mathrm{O}}{\mathrm{N}}$ & $\mathrm{d}$ & 0 & 123 & 0 & 0 & 5 & 0 & 0 & 0 & 0 \\
& $\mathrm{p}$ & 2 & 0 & 0 & 118 & 4 & 0 & 0 & 0 & 4 \\
& $\mathrm{t}$ & 0 & 4 & 0 & 12 & 108 & 0 & 0 & 0 & 4 \\
\hline & $\mathrm{b}$ & 109 & 1 & 0 & 8 & 0 & 0 & 1 & 1 & 8 \\
$\circ$ & $\mathrm{d}$ & 0 & 118 & 0 & 0 & 10 & 0 & 0 & 0 & 0 \\
$\circ$ & $\mathrm{p}$ & 6 & 0 & 0 & 73 & 1 & 0 & 0 & 0 & 48 \\
& $\mathrm{t}$ & 4 & 12 & 0 & 17 & 59 & 0 & 0 & 0 & 36 \\
\hline
\end{tabular}

Experiment 1 Dyslexic group -Intervocalic consonant

\begin{tabular}{|c|c|c|c|c|c|c|c|c|c|c|c|}
\hline & & b & $d$ & $p$ & $t$ & 1 & $r$ & $\uparrow$ & V & $\mathrm{m}$ & nul \\
\hline \multirow{4}{*}{ ○े } & b & 120 & 3 & 4 & 0 & 0 & 0 & 0 & 0 & 1 & 0 \\
\hline & d & 2 & 126 & 0 & 0 & 0 & 0 & 0 & 0 & 0 & 0 \\
\hline & $p$ & 0 & 0 & 128 & 0 & 0 & 0 & 0 & 0 & 0 & 0 \\
\hline & $\mathrm{t}$ & 0 & 0 & 1 & 127 & 0 & 0 & 0 & 0 & 0 & 0 \\
\hline \multirow{4}{*}{ ○̊ำ } & b & 127 & 0 & 1 & 0 & 0 & 0 & 0 & 0 & 0 & 0 \\
\hline & d & 0 & 122 & 0 & 1 & 5 & 0 & 0 & 0 & 0 & 0 \\
\hline & $p$ & 1 & 0 & 125 & 1 & 0 & 0 & 1 & 0 & 0 & 0 \\
\hline & $\mathrm{t}$ & 0 & 2 & 0 & 126 & 0 & 0 & 0 & 0 & 0 & 0 \\
\hline \multirow{4}{*}{ ڤั } & b & 95 & 9 & 2 & 0 & 14 & 2 & 0 & 1 & 0 & 5 \\
\hline & d & 1 & 119 & 0 & 1 & 7 & 0 & 0 & 0 & 0 & 0 \\
\hline & $p$ & 1 & 0 & 126 & 1 & 0 & 0 & 0 & 0 & 0 & 0 \\
\hline & $\mathrm{t}$ & 0 & 11 & 7 & 110 & 0 & 0 & 0 & 0 & 0 & 0 \\
\hline \multirow{4}{*}{ ஃ̊ } & b & 42 & 17 & 4 & 1 & 42 & 3 & 0 & 0 & 0 & 19 \\
\hline & d & 2 & 80 & 1 & 0 & 43 & 2 & 0 & 0 & 0 & 0 \\
\hline & $p$ & 3 & 0 & 121 & 0 & 0 & 0 & 0 & 0 & 0 & 4 \\
\hline & $\mathrm{t}$ & 2 & 17 & 10 & 77 & 1 & 0 & 0 & 0 & 0 & 21 \\
\hline
\end{tabular}

Experiment 1 Control group - Intervocalic consonant

\begin{tabular}{|c|c|c|c|c|c|c|c|c|}
\hline & & $b$ & d & $p$ & $t$ & 1 & $r$ & nul \\
\hline \multirow{4}{*}{ ठ̊ㅇํ } & b & 128 & 0 & 0 & 0 & 0 & 0 & 0 \\
\hline & $d$ & 0 & 126 & 0 & 1 & 0 & 0 & 1 \\
\hline & $p$ & 0 & 0 & 128 & 0 & 0 & 0 & 0 \\
\hline & $t$ & 0 & 0 & 0 & 128 & 0 & 0 & 0 \\
\hline \multirow{4}{*}{ 今̊ } & $\mathrm{b}$ & 126 & 0 & 1 & 0 & 0 & 1 & 0 \\
\hline & d & 1 & 126 & 0 & 1 & 0 & 0 & 0 \\
\hline & $p$ & 0 & 0 & 128 & 0 & 0 & 0 & 0 \\
\hline & $\mathrm{t}$ & 0 & 0 & 1 & 127 & 0 & 0 & 0 \\
\hline \multirow{4}{*}{$\stackrel{\circ}{\stackrel{\circ}{N}}$} & b & 111 & 5 & 1 & 0 & 4 & 5 & 2 \\
\hline & $d$ & 0 & 127 & 0 & 0 & 0 & 1 & 0 \\
\hline & $p$ & 1 & 0 & 127 & 0 & 0 & 0 & 0 \\
\hline & $t$ & 0 & 3 & 4 & 120 & 0 & 0 & 1 \\
\hline \multirow{4}{*}{ ○̊ } & b & 60 & 10 & 6 & 1 & 43 & 3 & 5 \\
\hline & d & 0 & 86 & 1 & 3 & 30 & 7 & 1 \\
\hline & $p$ & 4 & 0 & 121 & 1 & 0 & 0 & 2 \\
\hline & $t$ & 0 & 24 & 11 & 80 & 0 & 0 & 13 \\
\hline
\end{tabular}

Experiment 2 Dyslexic group -Attack consonant

\begin{tabular}{|c|c|c|c|c|c|c|c|c|c|c|}
\hline & & $b$ & $\mathrm{~d}$ & G & $p$ & $t$ & $\mathrm{k}$ & $r$ & $m$ & nul \\
\hline \multirow{4}{*}{ ᄋ̊ } & $\mathrm{b}$ & 118 & 4 & 0 & 4 & 0 & 0 & 0 & 1 & 1 \\
\hline & d & 6 & 115 & 0 & 0 & 7 & 0 & 0 & 0 & 0 \\
\hline & $p$ & 2 & 0 & 0 & 126 & 0 & 0 & 0 & 0 & 0 \\
\hline & $\mathrm{t}$ & 1 & 1 & 0 & 3 & 122 & 1 & 0 & 0 & 0 \\
\hline \multirow{4}{*}{ ठ̊̊ } & b & 118 & 5 & 0 & 4 & 0 & 0 & 0 & 0 & 1 \\
\hline & $d$ & 7 & 117 & 0 & 0 & 4 & 0 & 0 & 0 & 0 \\
\hline & $p$ & 5 & 0 & 0 & 121 & 1 & 0 & 0 & 0 & 1 \\
\hline & $\mathrm{t}$ & 1 & 3 & 0 & 4 & 117 & 1 & 0 & 0 & 2 \\
\hline \multirow{4}{*}{ 今̊ } & $\mathrm{b}$ & 122 & 1 & 0 & 4 & 0 & 0 & 0 & 0 & 1 \\
\hline & $d$ & 12 & 109 & 1 & 0 & 4 & 0 & 0 & 0 & 2 \\
\hline & $p$ & 1 & 0 & 0 & 119 & 2 & 0 & 0 & 0 & 6 \\
\hline & $\mathrm{t}$ & 0 & 2 & 0 & 3 & 121 & 0 & 0 & 0 & 2 \\
\hline \multirow{4}{*}{ ○̊ } & $\mathrm{b}$ & 115 & 4 & 0 & 4 & 0 & 0 & 1 & 1 & 3 \\
\hline & d & 37 & 78 & 0 & 1 & 8 & 0 & 0 & 0 & 4 \\
\hline & $p$ & 3 & 0 & 0 & 113 & 2 & 0 & 0 & 0 & 10 \\
\hline & $t$ & 0 & 2 & 0 & 10 & 107 & 0 & 0 & 0 & 9 \\
\hline
\end{tabular}

Experiment 2 Control group - Attack consonant

\begin{tabular}{|c|c|c|c|c|c|c|c|c|}
\hline \multirow{5}{*}{ ᄋ̊ㅇㅇ } & & $\mathrm{b}$ & d & $g$ & $p$ & $t$ & $\mathrm{k}$ & $\mathrm{nu}$ \\
\hline & $b$ & 128 & 0 & 0 & 0 & 0 & 0 & 0 \\
\hline & $d$ & 0 & 126 & 0 & 0 & 2 & 0 & 0 \\
\hline & $p$ & 1 & 0 & 0 & 125 & 2 & 0 & 0 \\
\hline & $\mathrm{t}$ & 0 & 1 & 0 & 6 & 120 & 1 & 0 \\
\hline \multirow{4}{*}{ ○̊ } & $\mathrm{b}$ & 127 & 1 & 0 & 0 & 0 & 0 & 0 \\
\hline & $d$ & 2 & 123 & 0 & 0 & 3 & 0 & 0 \\
\hline & $p$ & 0 & 0 & 0 & 128 & 0 & 0 & 0 \\
\hline & $t$ & 0 & 1 & 0 & 2 & 125 & 0 & 0 \\
\hline \multirow{4}{*}{ ڤ̊ํํ } & $\mathrm{b}$ & 128 & 0 & 0 & 0 & 0 & 0 & 0 \\
\hline & $d$ & 9 & 118 & 1 & 0 & 0 & 0 & 0 \\
\hline & $p$ & 0 & 0 & 0 & 127 & 1 & 0 & 0 \\
\hline & $t$ & 0 & 2 & 0 & 2 & 121 & 1 & 2 \\
\hline \multirow{4}{*}{ 今̊ } & $\mathrm{b}$ & 126 & 1 & 0 & 0 & 0 & 0 & 1 \\
\hline & $d$ & 45 & 80 & 1 & 0 & 1 & 0 & 1 \\
\hline & $p$ & 3 & 0 & 0 & 118 & 2 & 0 & 5 \\
\hline & $t$ & 0 & 1 & 0 & 4 & 112 & 0 & 11 \\
\hline \multicolumn{9}{|c|}{ Experiment 2 Dyslexic group-Intervocalic consonant } \\
\hline \multirow{5}{*}{ ○े } & & & b & d & $p$ & & & nul \\
\hline & $b$ & & 125 & 0 & 2 & & & 0 \\
\hline & d & & 4 & 124 & 0 & & & 0 \\
\hline & $p$ & & 0 & 0 & 126 & & & 0 \\
\hline & $t$ & & 0 & 1 & 0 & & & 0 \\
\hline \multirow{4}{*}{ ᄋ̊ํํ } & b & & 123 & 3 & 2 & & & 0 \\
\hline & d & & 1 & 127 & 0 & & & 0 \\
\hline & $p$ & & 1 & 0 & 127 & & & 0 \\
\hline & $t$ & & 0 & 1 & 0 & & & 0 \\
\hline \multirow{4}{*}{ 今̊ } & b & & 124 & 3 & 1 & & & 0 \\
\hline & d & & 3 & 124 & 0 & & & 1 \\
\hline & $p$ & & 0 & 0 & 126 & & & 2 \\
\hline & $\mathrm{t}$ & & 0 & 2 & 2 & & & 0 \\
\hline \multirow{4}{*}{ ○े } & b & & 127 & 1 & 0 & & & 0 \\
\hline & d & & 12 & 111 & 0 & & & 4 \\
\hline & $p$ & & 1 & 0 & 127 & & & 0 \\
\hline & $\mathrm{t}$ & & 0 & 1 & 4 & & & 0 \\
\hline
\end{tabular}

Experiment 2 Control group-Intervocalic consonant

\begin{tabular}{|c|c|c|c|c|c|c|c|c|}
\hline & & $\mathrm{b}$ & $\mathrm{d}$ & $\mathrm{g}$ & $p$ & $t$ & 1 & nul \\
\hline \multirow{4}{*}{ ઠ̊ } & $b$ & 128 & 0 & 0 & 0 & 0 & 0 & 0 \\
\hline & $d$ & 2 & 126 & 0 & 0 & 0 & 0 & 0 \\
\hline & $p$ & 0 & 0 & 0 & 128 & 0 & 0 & 0 \\
\hline & $\mathrm{t}$ & 0 & 0 & 0 & 0 & 128 & 0 & 0 \\
\hline \multirow{4}{*}{ ઠ̊ํ } & $b$ & 128 & 0 & 0 & 0 & 0 & 0 & 0 \\
\hline & $d$ & 2 & 126 & 0 & 0 & 0 & 0 & 0 \\
\hline & $p$ & 0 & 0 & 0 & 127 & 0 & 0 & 1 \\
\hline & $t$ & 0 & 0 & 0 & 0 & 128 & 0 & 0 \\
\hline \multirow{4}{*}{ ㅇํํ } & $b$ & 128 & 0 & 0 & 0 & 0 & 0 & 0 \\
\hline & $d$ & 1 & 127 & 0 & 0 & 0 & 0 & 0 \\
\hline & $p$ & 1 & 0 & 0 & 127 & 0 & 0 & 0 \\
\hline & $t$ & 0 & 0 & 0 & 0 & 128 & 0 & 0 \\
\hline \multirow{4}{*}{ ठ̊ } & b & 127 & 1 & 0 & 0 & 0 & 0 & 0 \\
\hline & $d$ & 7 & 114 & 1 & 1 & 0 & 1 & 4 \\
\hline & $p$ & 0 & 0 & 0 & 126 & 1 & 0 & 1 \\
\hline & $t$ & 0 & 0 & 0 & 3 & 123 & 0 & 2 \\
\hline
\end{tabular}


Our results show a time-compressed non-word auditory identification deficit for dyslexic adults compared to control adults that would be in favour of the auditory hypothesis. Indeed, in our task, the phoneme-grapheme conversion stage of classic speech perception model is not necessary to succeed the repetition task for dyslexic group. It is likely that dyslexics only took part in a direct auditory pathway to repeat the stimuli: they only have to decode stimuli at the first acoustic stage (acoustic features extraction). None phonological codes are needed to the dyslexic group to accurately identify non-words so we hypothesis that dyslexics probably show an auditory deficit in temporal processing and particularly in time-compressed speech. Rosen (2003) have reported a variety of auditory tasks that demonstrated an auditory processing deficit with dyslexia: a modulation frequency as well as a masking condition. However, in opposition with Rosen's opinion who affirms that the impairment is not due to rapid auditory processing deficit, we argue that our dyslexic adults displayed in all time-compression conditions significant identification deficit compared to control adults. Consequently, the rapid auditory processing would be impaired with dyslexia.

Further statistic analysis on errors' nature and nature of confusions showed specific identification deficit on consonant even at normal rate for dyslexics and it is worst and worst with the speech degradation.

In addition of this temporal processing deficit, we assume that cognitive restoration capacities of dyslexics are also deficient. The descendant auditory pathway might be a cognitive feedback to modulate the temporal resolution. Further hearing tests in order to evaluate the central auditory system of dyslexic adults would inform us on their central auditory abilities.

\section{Conclusion}

To conclude, our temporal modification on two different acoustic cues induced a loss of intelligibility for dyslexic adults that is significantly larger than control subjects. Dyslexics exhibit a deficit of accelerated acoustic cues integration (VOT and FT2); in particular, the inefficiency of the extraction and the manipulation of phonetic features are stronger for voicing compared to place of articulation. Finally, our results would be in accordance with the auditory hypothesis of dyslexia.

\section{Acknowledgments}

This research has been funded by the EMERGENCE program of the French Région Rhône-Alpes.

\section{References}

Foulke, E. (1971). The perception of time-compressed speech. In D. L. Horton \& J. J. Jenkins (Eds.), The perception of language. Columbus, Ohio: Charles E. Merrill publishing company.

Janse, E. (2003). Production and perception of fast speech. Doctoral dissertation, University of Utrecht.
Kent, R. D., \& Moll, K. L. (1969). Vocal-tract characteristics of the stop cognates. Journal of the Acoustical Society of America, 46(6), 1549-1555.

Lefavrais, P. (1965). Test de l'Alouette. Paris: E.C.P.A.

Lisker, L., \& Abramson, A. S. (1964). A cross-language study of voicing in initial stops: acoustical measurements. Word 20, 384-422.

Lisker, L., \& Abramson, A. S. (1967). Some effects of context on voice onset time in English stops. Language and Speech, 10, 1-28.

Merzenich, M. M., Jenkins, W. M., Johnston, P., Schreiner, C., Miller, S. L., \& Tallal, P. (1996). Temporal processing deficits of language-learning impaired children ameliorated by training. Science, 271, 77-81.

Meunier, F., Cenier, T., Barkat, M., \& Magrin-Chagnolleau, I. (2002). Mesure d'intelligibilité de segments de parole à l'envers en français. Proceedings of the XXIVèmes Journées d'Etude sur la Parole (pp. 117-120).

Mody, M., Studdert-Kennedy, M., \& Brady, S. (1997). Speech perception deficits in poor readers: Auditory processing or phonological coding? Journal of experimental child psychology, 64, 199-231.

Ramus, F. (2003). Developmental dyslexia: specific phonological deficit or general sensorimotor dysfunction? Current Opinion in Neurobiology, 13, 212-218.

Rosen, S. (2003). Auditory processing in dyslexia and specific language impairment. Is there a deficit? What is its nature? Does it explain anything? Journal of Phonetics, 31, 509-527.

Serniclaes, W. (1987). Etude expérimentale de la perception $d u$ trait de voisement des occlusives du Français. Doctoral dissertation, Université Libre of Bruxelles.

Snowling, M. J. (2000). Dyslexia. 2nd ed. Oxford: Blackwell Publishers Ltd.

Tallal, P. (1980). Auditory temporal perception, phonics, and reading disabilities in children, Brain and language, 9, 182-198.

Tallal, P., Galaburda, A. M., Llinás, R. R. \& von Euler, C. (Eds.) (1993). Temporal information processing in the nervous system. New York: New York Academy of Sciences.

Tallal, P., Miller, S. L., Bedi, G., Byma, G., Wang, X., Nagarajan, S. S., Schreiner, C., Jenkins, W. M., \& Merzenich, M. M. (1996). Language comprehension in language-learning impaired children improved with acoustically modified speech. Science, 271, 81-84.

Jacquier-Roux, M., Valdois, S., \& Zorman, M. (2002) Outils de dépistage des dyslexies. Académie de Grenoble: Laboratoire Cogni-Sciences et Laboratoire de Psychologie et Neuro-cognition.

Warren, R. M. (1970). Perceptual restoration of missing speech sounds. Science, 167(917), 392-393.

Ziegler, J. C., Pech-Georgel, C., George, FX., Alario, F. \& Lorenzi, C. (2005). Deficits in speech perception predict language learning impairment. Proceedings of the National Academy of Sciences (pp. 14110-14115). 